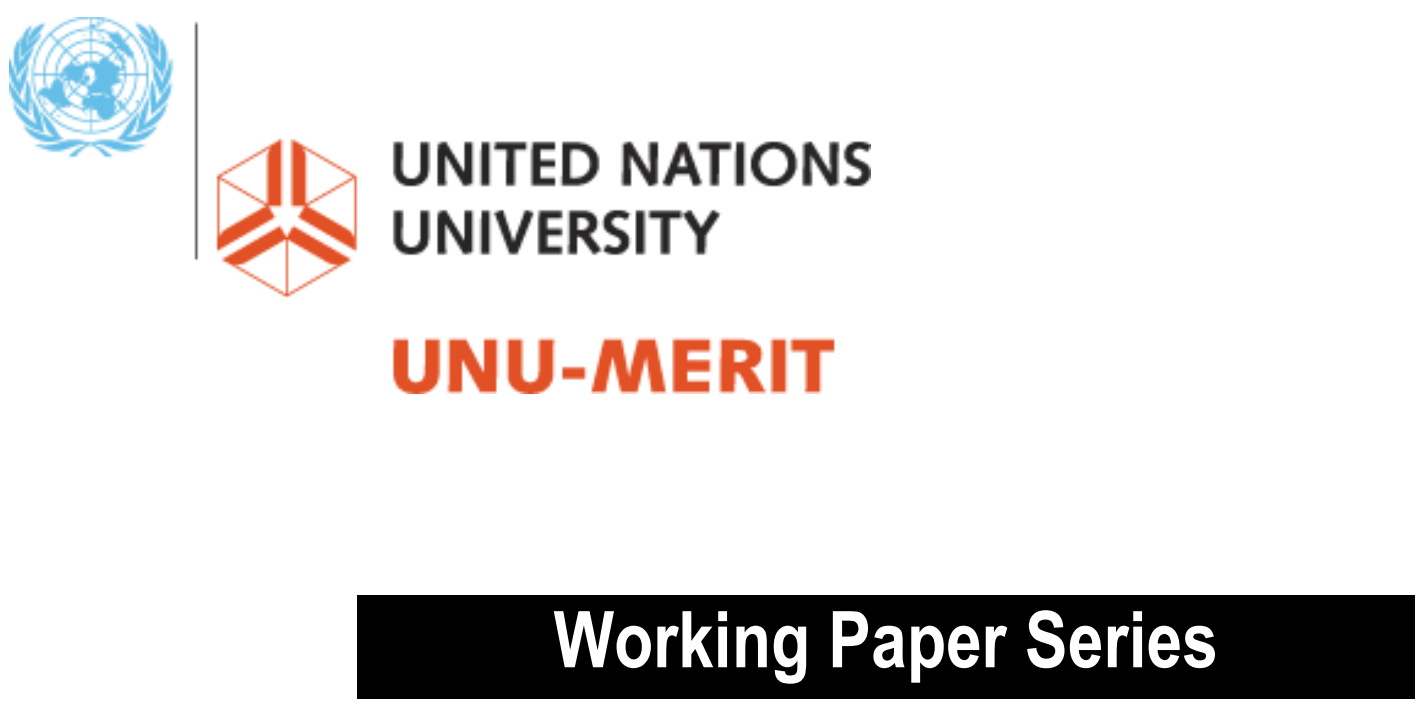

\#2008-043

Portrait of an Odd-Eyed Cat:

Cultural Crossing as a Trademark for a Dutch-Thai Strategic Alliance

Nantawan Noi Kwanjai \& J Friso den Hertog 


\title{
Portrait of an Odd-Eyed Cat: Cultural Crossing as a Trademark for a Dutch-Thai Strategic Alliance ${ }^{\S}$
}

\author{
Nantawan Noi Kwanjai \\ $J$ Friso den Hertog
}

\begin{abstract}
This chapter attempts a step forward in seeking a richer understanding of the dynamics of strategic alliances, specifically when viewed from a cross-cultural perspective. We report selected materials from a study designed to build a theory of culture and learning in organizations based on observations of and open-ended interviews with Dutch and Thai employees working for four selected Dutch firms in Thailand. Here we present one of those cases, a Dutch-Thai joint venture that thrived by weaving together the many intricate cultural webs to achieve a unique pattern of partnership which, metaphorically speaking, became its indispensible trademark. The case illustrates how the three levels of culture - national, organizational, and professional cultures - could all interlace in a real world setting and serve as an instrumental force of success amidst tension in one particular cross-border strategic alliance.

First, we adopt a thick descriptive style of case narration to present the case of a DutchThai joint venture, Chuchawal-De Weger Internationaal (CDW), painting a portrait of its origin, evolution and characteristics. Next, we turn to elaborate on the particular issue of cultural crossing, its exact theorized properties, dimensions and implications. Finally, we relate the case of CDW to the proposed theory and conclude with a reflection on how this case and our interpretation of it illuminate the complex role culture can play in the dynamics of strategic alliances.
\end{abstract}

Key words: cross-cultural management, culture, qualitative case study, strategic alliance, thick-description,

JEL codes: F23, L24, M16, Z13

\section{UNU-MERIT Working Papers \\ ISSN 1871-9872} Maastricht Economic and social Research and training centre on Innovation and Technology,
UNU-MERIT

\section{UNU-MERIT Working Papers intend to disseminate preliminary results of research carried out at the Centre to stimulate discussion on the issues raised.}

\footnotetext{
$\S$ This paper is under editorial review and to appear as a chapter in Ulijn, Jan, Geert Duysters and E. Meijer (eds) (forthcoming (2009)), Strategic Alliances and Culture: How Does It Matter? London: Edward Elgar Publishing. The study and this chapter would have been impossible if not for Chuchawal-De Weger Internationaal and its people who shared generously their experiences and insights, for which we can never repay but by sharing what we have learned with the wider community. We are also grateful to the reviewers, particularly Gert-Jan Hofstede, Rajesh Kumar and Jan Ulijn, whose critics, questions, comments and suggestions are intertwined with our labour in this final delivery. Any shortcomings remain our own. For contact: kwanjai@merit.unu.edu.
} 


\section{Introduction}

STRATEGIC ALLIANCES inherently dictate 'crossing' of cultures. Most particularly, when culture is conceived to include, as well as make distinction of, all levels and forms it can take - national, organizational, and professional, to list the most prominent in corporate world, as asserted in Ulijn (2000) - strategic alliances then involve cultural crossing at many levels. Although failures of strategic alliances are not uncommon (Park and Ungson 1997), impressive cases of success also abound (Mohr and Spekman 1994), motivating inquiries into the factors behind such opposing stories (Kogut 1988; Spekman et al. 1998). How can we explain, or rather understand, the dissolution or longevity of such partnerships that involve multifaceted crossing of cultures?

This chapter attempts a step forward in such understanding. We report selected materials from a study designed to build a theory of culture and learning in organizations based on observations of and open-ended interviews with Dutch and Thai employees working for four selected Dutch firms in Thailand (Kwanjai forthcoming). The key outcome of this work - a grounded theory of cultural intelligence that we label 'cross-cultural intelligence (XCQ) amidst intricate cultural webs' (Kwanjai and den Hertog 2008), emerged primarily from evidence in the four thick-descriptive cases. Here we present one of those cases, a Dutch-Thai joint venture that thrived by weaving together the many intricate cultural webs to achieve a unique pattern of partnership which, metaphorically speaking, became its indispensible trademark. The case illustrates how the three levels of culture expounded in this book - national, organizational, and professional cultures - could all interlace in a real world setting and serve as an instrumental force of success amidst tension in one particular cross-border strategic alliance.

First, we adopt a thick descriptive style of case narration (Chase 2005; Dyer and Wilkins 1991; Eisenhardt 1991; Simons 1996; Stake 1995; Stake 2000; Stake 1978; Stake 2005; Stake and Trumbull 1982; van der Blonk 2003) to present the case of a Dutch-Thai joint venture, Chuchawal-De Weger Internationaal (CDW), painting a portrait of its origin, evolution and characteristics. Next, we turn to elaborate on the particular issue of cultural 
crossing, its exact theorized properties, dimensions and implications. Finally, we relate the case of CDW to the proposed theory and conclude with a reflection on how this case and our interpretation of it illuminate the complex role culture can play in the dynamics of strategic alliances.

\section{Chuchawal-De Weger Internationaal (CDW)}

Chuchawal-De Weger Internationaal (CDW) is a Dutch-Thai joint venture consultancy providing services in civil engineering field with extensive expertise in architecture and building and prospective expansion into water and environment. CDW's portfolio of expertise include feasibility study, design, engineering, interior work, construction management, and project management. CDW's services span the range from conception, construction and maintenance of industrial and commercial facilities, office buildings, civil works, and infrastructure, with recent expansion to maritime works and water and environment. CDW has over 30 years of experience in Thailand and the South-East Asian region. A recent acquisition of its former Dutch parent (De Weger Architects and Consulting Engineers) by Royal Haskoning has made present day CDW a partially-owned but independently-run subsidiary of this top-notch Dutch engineering multinational consultancy group, a status which reaffirms as well as enhances its solid position in the Thai and Asian market.

\subsection{The origin}

In the early 1970s, a burgeoning Dutch civil engineering consultancy - De Weger Architects and Consulting Engineers - won a contract to design and manage a construction project for a new head office building for the Bank of Thailand. This was of a landmark caliber and an impressive achievement of De Weger's representative: Khun Geert Halsema ${ }^{1}$, especially since De Weger did not even have an office in Thailand at that time and was working only from its site in Indonesia. The nature of the civil engineering industry made it necessary to incorporate local presence and knowledge to meet legal requirements as well as to attain familiarity with native practices. Therefore, the Dutch firm sought and found a local partner in Design 103 - a young and dynamic Thai architectural firm founded and managed by a budding Thai architect, Khun Chuchawal Prempreecha. 
Although the initial intention of the alliance was only to carry out the one prestigious project, the union turned out to be quite a success, not only with regard to the project itself, but also, and perhaps more impressively, in relation with the resulting synergy of the two partners. Because of this success, the two companies decided to develop the partnership into a joint venture, CDW. Both of CDW's parent companies maintained their presence and continued their businesses as before - De Weger as an international Dutch engineering consultancy and Design 103 as a Thai architectural firm - while the offspring firm CDW concentrated itself on exploring a lucrative niche market, namely targeting multinational companies that were expanding their operations into Thailand and in need of architectural and construction expertise to set up their facilities.

\subsection{The evolution}

The two decades after the birth of CDW proved to be a prosperous period for the new alliance to exploit. The Thai economy was blooming into a little tiger, with an influx of huge multinationals, all wanting to establish firm footing in Thailand and the neighboring countries. CDW, with the prestige of its Dutch parent, could attract an impressive number of high-caliber projects from well-known multinationals, particularly those from the Netherlands and Western Europe. At the same time, with support from Design 103, CDW also steadily secured a stronghold among prominent Thai clients, governmental, non-governmental, and businesses alike. CDW's list of past, ongoing and repeated clients reads like a roll call of world-class businesses and agencies.

CDW grew impressively over the years, expanding its operations into other countries in the South-East Asian region and accumulating a remarkable portfolio of projects. Even though the Indonesian office of De Weger was its predecessor in the region for the Dutch parent, CDW Thailand was eventually established as the regional hub of the growing CDW group. This was partly due to the advantageous economic and political environment in Thailand and partly a result of the effectiveness of CDW Thailand itself. As of 2006, CDW had branch offices in Cambodia, Vietnam and the Philippines, plus representative or partner offices in China, India, Indonesia, and Malaysia. Externally, CDW operated independently from its parent companies but exhibited a strong tie with both. It was virtually the operating arm of De Weger, as it is now for Royal Haskoning, for the Dutch firm's Asian operations whereas close partnership with Design 103 continues until 
these. For all practical purposes, the three firms operate very much as one party, drawing resources from one another and capitalizing on the diversity of strength within the group.

When De Weger became part of Royal Haskoning in 2001, the plan was to continue capitalizing on CDW's reputable goodwill in the Asian market by letting the joint venture operate independently in its captured market of architecture and building while gradually injecting whatever extra capabilities the Dutch conglomerate has to offer into the local operation in Asia. To the outsider, however, CDW will still be the same reputable consultancy, only with even more 'promise' that was strengthened by the caliber of its adopted well-known Dutch parent.

As of 2006, the entire CDW group of offices in Asia employed a total of 400-plus workforce, with Bangkok as the home base. CDW's office in Bangkok (including Design 103) had about 250 employees, most of whom were local Thai staff in the middle management, professional (namely engineers, architects, draftsmen and construction supervisors) and supporting functions. The need for expatriates was only for high-level and special positions that require the expertise, seniority or caliber of expatriates. Generally, CDW had about such five expatriate posts, including that of President, which has always been held by a Dutch executive.

\subsection{The characteristics}

\subsubsection{Partnership of cultures}

CDW has a robust tradition of the strong Dutch-Thai partnership and takes pride in this. The company's name itself reflects a conscious effort to nurture this mutual respect - the Thai part of the name used the first name of the Thai co-founder rather than his family name, following Thai convention of formal addressing, while the Dutch spelling of 'Internationaal' purposefully signals its Dutch legacy. This conscious blend of the two heritages reflects both a desire and a necessity. Indeed, this unique blend of international/Dutch aura and local/Thai fluency eventually renders CDW the edge in its target market.

In the civil engineering consultancy business, what a firm virtually sells is a promise - a proposal of a product yet to be delivered. As such, CDW operates in an environment where prestige and reputation form the single critical success factor. With large organizations - commercial corporations as 
well as public agencies - as its client-base, CDW's products encapsulate engineering and architectural capabilities, visibly manifested only in successfully completed projects, in the form of landmark office buildings, prolific production plants, or celebrated public facilities and infrastructures. To win high caliber contracts that involve hefty outlay on the clients' part, CDW needs to constantly maintain and build on the image of its capabilities, by both capitalizing on past successes and cultivating new accomplishments. This requires a harmonious interplay between perceived and real qualifications: the alliance must make a convincing impression to win a contract, which, once won, must be followed by a finished project that at least meets or, better yet, exceeds that impression. Moreover, since CDW targets huge projects of high caliber and price tags, from clients that operated on global playing field, promises and achievements (or perceived and real capabilities) had to make up two sides of a coin for CDW.

In the same vein, global prestige and local stature also have to reinforce each other and make up two sides of yet another coin for CDW. This means CDW's daily operation represents a complex orchestration of myriad capabilities. Its core competency resides in its key professionals, the chief engineers and architects, whose professionalism and qualification mark the beginning and conclusion of a project. At the same time, the supporting teams of project management, construction and interior work, and quality control must operate to carry out their functions effectively to ensure that each project is delivered as conceived, planned and pledged. Additionally, CDW also needs to cooperate well with all external parties including outside contractors governmental agencies, and most importantly, the clients, throughout a project life cycle to guarantee satisfactory completion as well as to preempt costly rework.

Partnership is thus the origin and lifeblood of CDW - partnership of myriad actors, activities, functions, professions, entities, agendas, interests, or in a nutshell, partnership of cultures at many levels and in many ways, shapes and forms. MMM

\subsubsection{An ideal match: a tale of two founders}

Sitting now in a quiet, cosy living room of his apartment in Leiden, the Netherlands, Khun Geert, the Dutch co-founder, often reminisced about the many memorable years he lived and worked in Thailand. He was back 'home' 
now, in a sense, since this country was where he was born and raised. Yet, in a way, here was no longer entirely his home, well, not his only home at the very least. After over four decades outside of his native land, a large proportion of which in Bangkok, Thailand, he and his wife had eventually retired to their home country to be closer to the children and grand children. To his mild surprise, he found himself having to grow back to the Dutch culture. At the shop the other day, for instance, he found himself feeling affronted when addressed by a young assistant with the familiar 'je' instead of the respectful ' $u$ '2. This would never happen in Thailand. No young Thai would behave that way to a man of his maturity and stature.

This was nothing new to Khun Geert, of course. He had done it many times before, this 'growing into' an unfamiliar way of living. As a lifelong expatriate, Khun Geert learned early on that one had to adapt gradually to a new culture if one were to survive and thrive in it. Of his years in Thailand, he was glad that the adapting experience turned out to be pleasantly memorable. For that, he believed he owed it to a partnership he had with his Thai counterpart, Khun Chuchawal, the Thai co-founder of CDW. As a matter of fact, Khun Chuchawal has eventually become not only a fine business partner but also his lifetime friend.

To Khun Geert, their partnership was a true partnership, an ideal match, if there was such a one. Khun Geert considered himself lucky to have Khun Chuchawal as his counterpart in the Dutch-Thai alliance when he first entered Thailand. They complemented each other well and operated on equal footing. He remembered fondly the usual shouting matches they had had over the years and how he appreciated greatly that Khun Chuchawal would be comfortable with direct confrontation, without ever making a personal fuss about it afterwards, as most Thais would have. The usual shouting matches would transpire; frictions get sorted out; and their partnership and friendship keep on without a dent, so to say. Things would not have been as smooth and productive if Khun Geert had to struggle with the usual roundabout Thai way in his dealing with a Thai partner when the business was still in its infancy. Indeed, many a time Khun Geert wished that he could find this raw honesty in other members of his Thai colleagues and staff. The memory reminded him of the one thing he liked about Khun Chuchawal - the upfront, say-it-as-it-is style that gave mystery not a chance and left the air clear and easy to breath. 
Hence, they learned to use each other, to exploit each other's complementary quality for the benefit of a mutual business advantage. Khun Geert focused his effort on developing CDW for the then parent De Weger and he certainly needed the rare, almost ideal, blend of quality he found in Khun Chuchawal: local familiarity, Western sympathy, and honest, Dutchlike, direct interpersonal style. Khun Chuchawal, as a Thai who appreciated the value of Western know-how for a still developing economy of Thailand, welcomed the advanced technical expertise that he could tap into through the Dutch-Thai alliance. More, he could even use the Dutch blunt approach, in the living figure of Khun Geert, to achieve certain results with his own countrymen when he knew he himself could never do so as a Thai. When the 'kraeng jai'3 value could get in the way of business, he would turn to Khun Geert to cut through it, since the Thai would not take to a direct approach so seriously when it came from a 'farang'. Khun Geert, on the other hand, relied on Khun Chuchawal to share openly and honestly the local fluency that he needed to run CDW effectively. Thus, although heading two seemingly different companies: Khun Geert as the CDW's President and Khun Chuchawal as Design 103's Director, the two co-founders of CDW operated virtually as one team, one family.

Their synergic partnership indeed fuelled the eventual growth of all the business entities they founded and managed. It also established the identity of the sequel of their initial alliance, in more ways than one. Even when both co-founders has retired, the legacy of their intriguing partnership still permeates the present CDW/Design 103 group in the very fabric of its organizational culture. As for the origin of that legacy, the tie still binds. Both Khun Geert and Khun Chuchawal maintain an advisory role in the CDW/Design 103 group and their experience benefits the current generation. Personally, they remain close friends and enjoy each other's company on a regular basis, while their mutual legacy continues to operate successfully and shows no sign of slowing down.

\section{Modes of cross-cultural condition}

\subsection{Culture}

Culture is a concept that defies universal definition. Any definition of culture is in essence a statement of what the definer perceives as its most important 
aspect (Kroeber and Kluckhohn 1963). In our study, we conceptualize culture as an intricate web of shared meanings that underlies two basic social processes: 1) cognitive processes, which make sense of and interpret all an individual encounters, whether material objects, social happenings, or mental concepts; and 2) behavioural processes, which comprise action, inaction, and interaction, depending on the meanings given to each object or

event. Thus, culture is a shared way of being and sense-making that is unique to a distinct group of people and can distinguish that group from others.

From this perspective, culture influences how people think, feel, and act, not in a one-to-one manner, but through their interpretations of the thoughts, feelings, and acts of those they come into contact with. Yet surprisingly, with the notable exception of anthropologist Clifford Geertz (1993), most prominent cultural theorists have paid little, or virtually no, attention to this interpretive influence of culture, which our study has shown to be a vital aspect of cultural dynamics. Indeed, in our study finding, this interpretative influence of culture is the prime, and supremely significant, force in any cross-cultural encounter because it fundamentally drives the directive influence. In other words, individuals think, feel, and act based on the meanings they give to the objects of their thoughts, feelings, and acts.

\subsubsection{A cultural onion model}

One widely accepted symbol of culture's internal dynamics is the cultural onion model (Adler 2002; Hofstede 2001; Schneider and Barsoux 2003). Although there are as many variations of the cultural onion as there are cultural theorists, all variants of the model, ours included, share the following fundamental messages. First, culture manifests itself in diverse ways, shapes and forms - ranging from the most visible to the least fathomable - that may be likened to the many layers of an onion. The most easily seen and comprehended cultural layers are those on the outside, which include material objects, costumes, verbal and non-verbal languages, and architectures. The less visible inner layers comprise institutions and various cognitive attributes.

Second, most theorists would go on to state that all these layers interrelated in a particular fashion. The most widely theorized relationship is that 
the inner layers influence the outer layers, and the innermost layer, or cultural core, is the key to all the influences. From this point, though, the diverse cultural onion models vary in two respects: 1) what components make up the layers and what their relative positions are (including which elements constitute the core); and 2) the exact nature of the onion's internal dynamics. We illustrate in Figure 1 the cultural onion conceptualized for our theory. It should be noted, however, that this representation of culture's internal components only attempts a pragmatic classification: it is not a strict portrayal of the complex abstract phenomenon under analysis. In actuality, the relationship among the layers is not a straightforward unidirectional correlation, a fact that foreshadows the concept of intricate cultural webs.

Figure 1 A cultural onion model

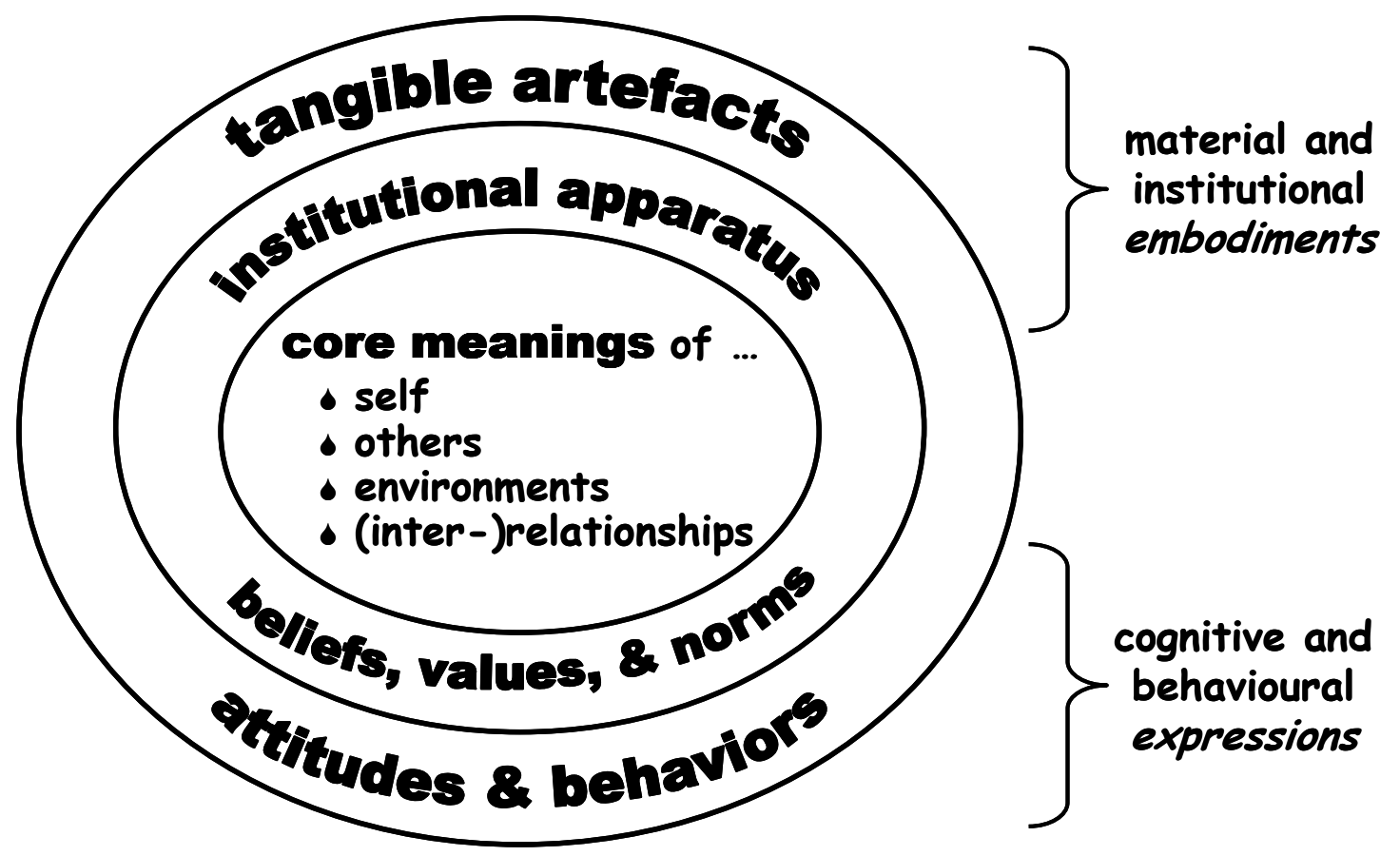

Source: Authors' conceptualization.

\subsubsection{Level of culture}

Level of culture refers to the external associations of culture and involves its properties and boundaries. The property of a culture is the glue that holds a cultural group together - a set of unique attributes that identifies the group as distinct from other groups. For example, national culture has a complex set of attributes, the most prominent of which include geographical border, 
nationality, legal legitimacy, a political system, an economic system, social institutions, and a history, among the most prominent. The boundary of a culture is the limit of its properties and hence of that culture. For example, a national culture is bounded by its geographical boundary, which is physical and definite. However, a boundary can also be abstract and flexible, such as that which defines a particular clique or team. Whichever the case, a boundary signifies the coverage of a particular culture's influence and can be classified into two major categories of cultural level: the formalized and the incidental. These are summarily catalogued in Figure 2.

Figure 2 Major categories of cultural level and their sub-categories

formalized level

\begin{tabular}{|c|}
\hline formal $\sim$ hierarchy \\
\hline global \\
regional (continental) \\
national \\
regional (provincial) \\
sectoral \\
industrial \\
organizational \\
departmental \\
team
\end{tabular}

incidental level

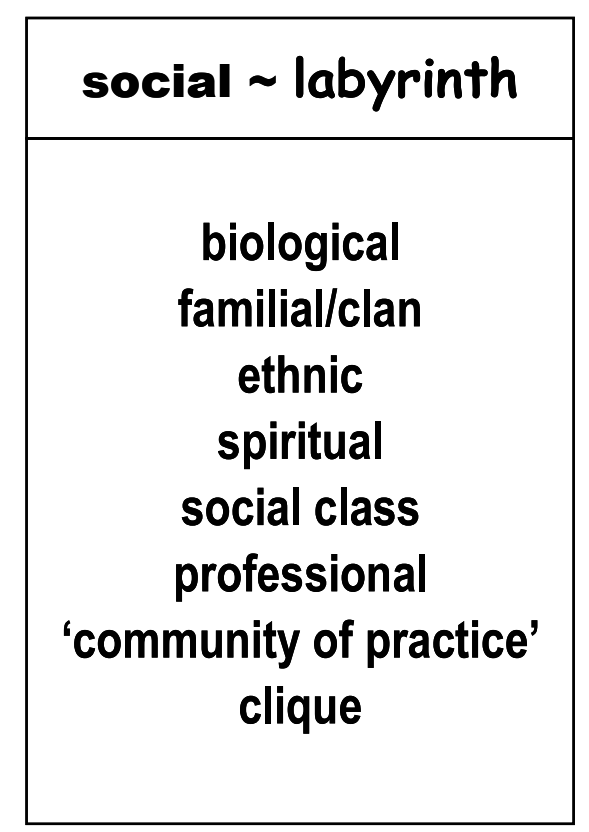

Source: Authors' conceptualization.

\subsection{Intricate cultural webs}

The concept of 'cultural web' of meanings is obviously not new, having been rigorously presented by Clifford Geertz (1993), whose conceptualization very much foreshadowed the expanded interpretation we propose here. Two concepts underlie this image of the cultural web: a 'cultural unit' - an entity or group of entities whose individual or collective identity is shaped by one or 
(most likely) multiple cultures, and a 'cultural identity', which refers to the combined cultural forces within a cultural unit, whether an individual, group, organization, nation, and so forth. Because a cultural unit, even if an individual, invariably belongs to or is made up of more than one cultural groups or levels, its property can be depicted as a cluster of many cultural onions. The underlying condition of such a cultural unit constitutes its cultural identity, which has the following properties. First, it is a complex web of cultural layers and levels to which a cultural unit belongs, of which it is made up, and by which it is constantly being influenced. Second, it is always in flux, shaping and re-shaping itself as the unit continues to operate in a variety of environments. Third, its focal point of cultural stimulus is constantly changing dependent on a particular context.

Cultural webs characterise both a cultural unit and a cross-cultural condition, two constructs that share one critical property: both are made up of a multitude of cultural webs - complex networks of interlacing cultural layers and levels. Such cultural webs themselves have one key property: the exponential complexity that inspired our choice of the metaphor intricate cultural webs'. Even in simple situations like one interaction between a Dutch manager and a Thai subordinate, the entire event actually operates under the forces of a multitude of cultures and sub-cultures, all of which comprise many complex layers. Thus, every analysis must effectively examine multiple, complex, and complicated cultural webs and all their forces.

\subsection{Modes of cross-cultural condition}

Because the term 'cross-cultural' takes on ambiguous and confusing definitions in the literature but serves an imperative choice in our study, we must first justify and establish its exact meaning. Traditionally, the term 'cross-cultural' designates mostly its comparative connotation: 'cross-

cultural studies' typically stand for comparative studies of different cultures, mostly national. This has to do with the history of cross-cultural research in general and cross-cultural management studies in particular, for both of which comparative inquires dominated the early phase (Adler 1983; Boyacigiller et al. 2004; Roberts 1970). However, recent debate has raised the need to expand the meaning of the term to reflect greater sophistication in the field. For example, Jackson and Aycan's early proposition (Jackson and Aycan 2001: 7-8) elaborated extensively on the fine distinction between 
'international' and 'cross-cultural' research but still resonated the notion that cross-cultural studies involved mostly, if not exclusively, a comparative element. Five years later, they moved to argued that although '[c]ross cultural theory has developed strength in comparing nations (as the cultural unit of analysis) in terms of broad value dimensions, ... little attention has been paid to cross cultural interactions or interfaces as the unit of analysis' (Jackson and Aycan 2006: 10, emphases original). They argued further that [c]ross cultural interactions and interfaces at multiple levels including intercontinental, inter-national, inter-ethnic, inter-group, interorganizational levels' must be one of the pressing issues for future crosscultural research (Jackson and Aycan 2006: 11). Our study's finding corroborates their proposition.

Hence, the meaning of the term 'cross-cultural' must expand to designate issues involving different cultures not only from a comparative angel, but also, and most specifically, from an interactive viewpoint - namely at their interfaces or 'crossings'. Thus, although the ambiguity of the term 'cross-cultural' in the literature instigated a dilemma during the earlier theorizing phase in our study, we prefer the term over its alternative, namely 'intercultural', solely by virtue of the significance of the word 'cross.' Specifically, the subtle implication of the term 'cross' in relation to cultural interfaces emerged as a crucial concept in the eventual grounded theory in our study, compelling us to retain its use despite the lingering tendency to associate the term solely with its comparative connotation. To emphasize, 'cross-cultural' here signifies not only a comparative aspect but also, and even more importantly, an interaction element of a cross-cultural phenomenon. In this light, strategic alliances such as CDW inherently involve crossing in both dimensions - comparative and interactive - of more than one culture, and at many levels. Specifically, though, the emphasis of our elaboration is on the interactive aspect of the term 'cross.' That is, the locus of our analysis is not the nature of our focussed entity - namely, culture, but rather that of its interactive feature - namely a cross-cultural condition.

What then is the importance of the crossing factor in our conceptualization? First, simple dictionary definitions of 'cross' usually denote several subtle modes of interaction of which clashing is only one. When applied to crossing of cultures, in reality many possible conditions can result. Our study evidence suggests three distinct modes of crossing when 
cultures cross or interact: clashing, reciprocal, and hybrid. These modes are summarised Table 1 which serves as the framework for subsequent discussion.

Table 1 Modes of cross-cultural condition

\begin{tabular}{|l|c|c|c|}
\hline \multirow{2}{*}{ KEY PROPERTIES } & \multicolumn{3}{|c|}{ MODES OF CROSS-CULTURAL CONDITION } \\
\cline { 2 - 4 } & clash & reciprocal & unification \\
\hline DOMINANT CATALYST & difference & mutuality & affinity \\
\hline PREDOMINANT INTERACTION & conflict & exchange & cultivation \\
\hline KEY INSTRUMENT & controller & mediator & hybridizer \\
\hline STEADY STATE RESOLUTION & $\begin{array}{c}\text { either assimilation, } \\
\text { division } \underline{\text { or separation }}\end{array}$ & combination & hybrid \\
\hline MATHEMATICAL ANALOGY & $1+1=1, \frac{1}{2}$ or 0 & $1+1=2$ & $1+1>2$ \\
\hline
\end{tabular}

Source: Authors' conceptualization.

\subsubsection{Key properties of cross-cultural condition}

The first property when cultures cross relates to its 'dominant catalyst', which refers to the primary force in the interaction. This signifies what the actors identify as the salient ingredient of a particular cross-cultural condition - the initial or primary engine that motivates their interpretation of the thoughts, feelings, and acts of themselves and others within that crosscultural context. Next, the property 'predominant interaction' refers to the most prevailing activity in an interface, which correlates strongly with the dominant catalyst. Third, the property 'key instrument' relates the primary mechanism used in order to carry out the predominant interaction and bring about the possible steady state resolution. Last, the property 'steady state resolution' signifies a state of a cross-cultural condition that is sustained over a certain period ${ }^{5}$. Steady state denotes a sustained but not static condition because a certain cross-cultural phenomenon may start in one mode but later develop into another mode altogether. Finally, a mathematical analogy for each of the three modes serves a simple inferential device. 
For the purposes of this chapter, three important points should be made about this taxonomy. First, our theorizing involves no underlying judgement about the modes of cross-cultural condition: the taxonomy simply reports the range of options and possibilities indicated by our grounded evidence. Thus, any assessment of one mode's superiority to others is relative to the situation. What is informative and valuable is an understanding of what contributes to a particular situation's engendering of one mode rather than another and the consequences of such a development. Second, rather than deriving an exhaustive list of all possibilities, which would render the taxonomy redundant and cumbersome, the three modes indicate the range of possibilities that may characterize a cross-cultural condition. Lastly, these three modes are not mutually exclusive in a single cross-cultural situation: more than one mode may (and usually does) coexist in a cross-cultural context or within intricate cultural webs. The key is to discern what mode is the dominant one for a particular phenomenon under analysis and what that entails.

\subsubsection{Clashing mode}

The clashing mode is one in which difference denotes the dominant catalyst and conflict often emerges as the crux of the interface. This is the most recognized and recognizable of all the modes because of its vivid nature and persistent prevalence. Indeed, this is the mode identified as the most significant by many prominent cultural theorists such as Hofstede and Huntington (Hofstede 2001; Hofstede 1980; Huntington 1993). In this mode, difference between cultures significantly, if not solely, influences how actors interpret and act. By 'difference', under our interpretative analytical lens, is the difference in meanings given to concepts, entities or acts. The fixation on difference often, though not necessarily always, leads actors to contemplate conflict, because one meaning will want to exert its force on its counterpart. When this happens, the key instrument is generally a sort of controller something that renders one party the ability to govern the situation in the direction of its own meaning. A controller can be in any form that ranges from formal authoritative power to subtle manipulating tactic. Whatever form a controller takes, its main effect is to establish the meaning in one culture as the governing meaning of the cross-cultural situation. In the clashing mode, there are three possible steady-state resolutions: assimilation, division or separation. Assimilation occurs when one cultural 
meaning totally subsumes the other(s), thereby effectively eradicating the forces of all other competing meanings. Division results when the differing actors from different cultures maintain their own meanings but still operate in the cross-cultural context in which conflict persists. Separation transpires when actors from all involving cultures go their separate way, terminating the cross-cultural condition altogether.

Obviously there are numerous everyday examples of the clashing crosscultural mode. The one identified by Huntington, for example, is believed by many to characterize today's world affair according to his proposed thesis (Huntington 1996a; Huntington 1993; Huntington 1996b). The clash of civilizations theory, in brief, predicts international relations to operate with cultural difference as the key catalyst and conflict persists and characterises the relationship among major cultures of the world. Hofstede's work provided countless examples illuminating how difference among cultures in organizations and societies could result in vivid tension (Hofstede 2001; Hofstede 1980; Hofstede and Hofstede 2005).

Summarily, the clashing mode is the most prevalent mode and invariably exists in most cross-cultural conditions, especially at the initial crossing stage, but not necessarily as the only lasting dominant mode. Even so, in many cross-cultural encounters, this mode could so persist that it then becomes the dominant mode.

\subsubsection{Reciprocal mode}

The reciprocal mode has some sort of mutuality as its main force. In this mode, the focus of the actors involves some kind of mutual interest, desire, need, goal, and the like. Thus, mutuality refers to a common target that can only be achieved by having actors from the different cultures contributing inputs that are unique to their own cultures. Such a situation occurs when actors from each of the cultures have what the others do not have by virtue of their distinctive cultural heritage. In this mode of crossing, the focus of the interaction is mainly exchange, meaning straightforward give and take, where some sort of mediator is the key instrument. Actors from one culture give what those from other culture need but lack, and vice versa, in order for all to achieve a mutual target - hence the label reciprocal. The steady state resolution of a reciprocal cross-cultural condition is a straigthforward combination of cultural meanings that retain the essence of their original 
cultural sources, without critical change or adaptation. In simple term, this is an uncomplicated case of one plus one equal two, as in basic mathematics.

This second crossing mode is less easily recognizable but exists more often than most people realize. The case of CDW, the odd-eyed cat, is a vivid example of such a cross-cultural condition. CDW thrives on a reciprocal cross-cultural condition because its key strategy and trademark, local fluency with international expertise, is a mutual target of all concerned and can only be achieved by having each of its key cultural groups, particularly the national cultures Dutch and Thai, retaining or even brandishing its own cultural essence - an issue to be revisited in subsequent sections.

\subsubsection{Unification mode}

In the unification mode, actors' affinity with the meanings in the other culture denotes the dominant catalyst. This mode is, in a simple sense, the reverse of the clashing mode and one step beyond the reciprocal mode. In this mode, actors in a culture discern that actors from the other culture have different meaning than that in their own, yet find it to be more admirable and desirable. Thus, in this mode, what is reciprocal is a fundamental affinity between actors from different cultures, each admiring, not merely in want or need of, elements or meanings in the other culture that do not exist in its own. In this mode, the predominant interaction is cultivation, because actors will attempt to assume the desirable meaning and make them part of their system of meanings. For this cultivation, a sort of hybridizer is the needed instrument. A hybridizer signifies a mechanism that fuses various competing meanings into one new system of meanings altogether. Such fusion evolves from genuine appreciation and aims at creating a new fused meaning hitherto not in existence. A hybrid entity - a novel entity entirely - then emerges as a result of this cultivation.

A cross-cultural unification and its hybrid creation may be more common in everyday life than most would imagine. An immigrant, who is well received by and has integrated well in a new country, is a good example. Such an individual has developed a new national cultural identity, at his own individual level, that is neither his birth culture nor the adopted one, but actually a fusion of both. His new cultural identity reflects some cultural traits from his own motherland, some from the adopted country, and some 
totally new but with influences from both. A successful mixed marriage is another everyday life example. In such a household, elements from all involved cultures blend together to form a new unique household, a hybrid cultural group.

\section{CDW as an odd-eyed cat}

Given the above view of modes of cross-cultural condition, we locate CDW, at the time of our narration, as a curious combination of cultures - an instance of the reciprocal mode. If CDW were to be a biological entity, its appearance would probably carry a telltale sign of its reciprocal cultural steady state resolution. CDW might then be akin to those peculiar creatures, the oddeyed cats (ones with each eye being a different color, such as one blue eye and one orange or copper eye). This is a striking but apt analogy, for CDW thrived on an odd combination of various partnerships: odd in that all the partnerships at CDW were based on one crucial characteristic: the need for each partner to uphold its own unique quality while contending with and exploiting the unique quality of the other partner(s) at the same time. In such a particular form of partnership, if one partner were to be completely absorbed into the other's identity (either through assimilation or hybridization), the partnership itself would no longer work, hence the aptness of the odd-eyed cat analogy - each eye needs to retain its distinct color, for the creature to earn the title of an odd-eyed cat. This may sound rather obscure, so let us scrutinize the many odd-eyed partnerships at CDW.

\subsection{Partnership of nationals}

A key policy at CDW was always, as Khun Karel Westerveld, CDW President, put it, 'local expertise with international standard'. In simple terms, 'local' meant Thai while 'international' meant Dutch or Western (as a touchstone for international standard). But what did the policy really mean in real terms?

The requisite need for local expertise was driven of course by the nature of the industry the alliance operated in. For one thing, in the construction and architectural industry (as in other professional fields such as law, medicine, and accounting), legality always mandates locally certified 
professionalism, the very first reason why Khun Geert needed the locally certified architect, Khun Chuchawal, to 'sign off' their initial landmark project. However, legality is but the tip of the iceberg since local expertise also involves an on-the-ground familiarity with local practices, preferences, and quirks, some of which are too subtle for an outsider to recognize, let alone appreciate.

To give an obvious example, even though the Thai do not subscribe strictly to such belief as the Chinese 'feng shui', they do observe a looser form of such practice. A building front gate needs to be positioned in such and such a way in order to induce stability and prosperity. Internal arrangement of different types of rooms and spaces should follow certain principles to ensure physical and spiritual harmony. One does not sleep with one's head towards the South or the West; else one may be subject to inferiority or misfortune (because another meaning of the Thai word 'South' is 'to be under' while that of 'West' is 'to fall'). Certain colors are not to be used for such and such spaces or purposes. And so on, so forth. Thus, it is not uncommon in Thailand to have a building torn down or renovated to 'correct' spiritual (not physical) mistakes. As a result, a religious-cumspiritual ceremony performed on sites always marks the inauguration of a construction project, particularly a major one. This ritual requires an involvement of many experts in diverse specialized teachings, an occasion that would pose average foreigners quite a challenge to orchestrate. No wonder CDW needed local expertise to help carry out its business. Ignorance or inobservance of such seemingly immaterial familiarity could spell disaster. And this represents but one example of the many instances of local familiarity that played a subtle yet influential role in the daily operation of CDW.

On the other hand, CDW's particular choice of niche market compelled the need for an international caliber. CDW's clients comprised major players in the global scene, the majority of whom were big name multinationals that needed to observe international standard in all its facets, particularly that of industrial, environmental, and quality control. The Dutch ownership of CDW in effect created a trademark of international standard for the alliance. Indeed, as Khun Chaowalit Saenamuang, one of CDW's key Project Managers, put it: 'When I deal with Western clients, I'm practically selling 'farangs' or 'Westerness' if you know what I mean. To be honest, I think some of the Thai engineers and architects may be better at their functional tasks 
than their expatriate counterparts may, well, at least better at those here in Thailand for sure. But I can't sell Thainess to the 'farangs'. They won't buy it. It's just a fact of life and you've simply got to take it or leave it.' So, for many such projects, Khun Chaowalit needed to put upfront the appropriate expatriate professionals to cultivate the expatriate clients' trust. These expatriate professionals of course earned expatriate pay, which drove up project costs considerably. Still, the majority of CDW's multinational clients were more than willing to pay higher prices for such a trademark. It did not really matter if in many cases the actual projects might make heavy use of the internal Thai expertise at CDW, or Design 103. First was to secure a project. And if it took the expatriate' stamp for that, so be it.

But international standard was in many senses more than just a literal stamp. As with local expertise, CDW's tie with Western know-how and practices also carried a unique quality of material value. In an industry where advance in technology is critical, Western experience and know-how did give CDW a cutting edge. Khun Geert, the Dutch co-founder, remembered how he needed to bring people in from the Netherlands to train his Thai professionals on CAD/CAM technology during the early years. Khun Chuchawal, the Thai co-founder, valued the Dutch-Thai partnership, first and foremost, because he knew that it was the best way to tap into Western know-how and move Thailand forward. Khun Karel, the current President, knew for certain that in some areas, such as quality control or the specialized field of water and environment, the Thai had quite a bit to learn from the Dutch. Khun Chaowalit himself professed genuine respect for the Dutch expertise with waterworks.

And that is that. The Thai are good at some things and the Dutch at others. At CDW, they both needed each other's unique quality to create the unique blend of cultural identity. More, each needed to excel at their quality in order to reinforce the eventual combined identity, at least at the 'appearance' level, and more importantly at a more profound level. Still, the odd-eyed appearance could be a cause of unavoidable rift and tension. Two Thai employees, Khun Chaowalit, the Project Manager and Khun Busara Navarat, Executive Secretary to the President, for example, witnessed on a regular basis how such 'keeping up appearances' could cause resentment among the Thai staff and create friction between the local and the expatriate.

Looking from the Dutch expatriates' view, the higher prestige and pay were of course not much more than they would earn in the Netherlands. It 
would make no 'Dutch' sense, at the very least, to expect them to be rewarded the same rate as the local Thai. Most qualified Dutch professionals would expect at least the same reward they would get in the Netherlands, if not more, for coming to work in a foreign country. With the cost of living in the Netherlands and Thailand being starkly different, this situation would not change any time soon.

Still, many fine Thai engineers and architects at CDW could not help feeling it was not quite fair for them to earn a lot less for the same type of work (that they were often better at) simply because they were Thai. Khun Busara sympathized very much with her Thai colleagues. They were quality people and their loyalty to their professions and the alliance was unquestionable. She understood their sentiment perfectly and it pained her to witness the undercurrent of this 'double standard'. She questioned whether the need to impress Western clients was justification enough for the double standard and even if it was, that still did not make the situation any less unfair. Khun Chaowalit couldn't agree more. A fine Thai engineer himself, he could hold his own with any Westerner in his functional capability. Yet, he could not have secured as many prestigious projects as he had done, if he had not had the 'Westerness' as a trademark of his ware. Trademark was nothing but appearance, of course. But it was somehow an appearance that was more than skin-deep. It would have been fine, of course, if business would allow CDW to upgrade all Thai professionals to earn the same as their expatriate counterparts. Yet, that would surely render CDW's service ridiculously expensive and utterly uncompetitive in the Thai and Asian market. At the end of the day, it was the bottom line that counted and Khun Chaowalit's job hinged on the kind of bottom line that necessitated the double standard. So double standard it must be, then.

Odd as it is, the odd-eyed quality that CDW boasted was unavoidable as well as indispensable, even though it may be a cause for many concerns. As Khun Chaowalit put it, 'It's just a fact of life and you've simply got to take it or leave it!'

\subsection{Partnership of professionals}

Unfortunately, the inevitable friction between the Thai employees and Dutch expatriates was not the only tension Khun Chaowalit had to deal with. As a project manager, he also had to orchestrate the many departments within 
the group so that they worked in harmony and brought each and every project to a successful completion. He would not say it was a simple task. For one thing, he was constantly spinning at the center of all functional divisions: conception and design, budgeting, procurement, construction, interior work, and quality control. In effect, as a project manager, Khun Chaowalit operated at the hub of the many partnerships of professionals and functions at CDW.

Of course, each profession has its own professional culture that influences the beliefs, values and norms of the community and informs their attitudes and behaviors. Thus, at CDW, tension emerged whenever two or more professional groups needed to come together and cross each other's comfortable zones, signifying another crossing of 'cultures - 'professional' cultures, that is - which Khun Chaowalit must turn into a partnership rather than a combat. This partnership of professionals had the same principle that drove the partnership of nationals at $\mathrm{CDW}$, that is, each professional group must excel at its own expertise while contending with and exploiting the unique expertise of the other partner(s).

Let's take the case of procurement and quality control as a vivid example. Procurement people's main concern was to keep to the budget and schedule. Not that they were eager to sacrifice quality but their foremost 'bottom line' items were first the timely and correct delivery of materials and, second and most importantly, the cut-and-dry figures in the final project account. Therefore, cutting corner might come into play, compelling quality control professionals to step in and have their say. Indeed, the interplay between budget, time and quality control could easily make or break a project. Khun Chaowalit, again as project manager, must make sure that an optimal balance was struck, with the least discord possible. Far from a piece of cake!

Additionally, Khun Chaowalit witnessed yet another partnership of professionals at $\mathrm{CDW}$, that of the engineers, the architects, and the interior designers, three closely related but distinct professionals who took great pride in their expertise - pride that could sometimes turned into prejudice against the other professions. At the same time, each party had to have enough respect and confidence in the other's expertise in order to carry out their mutual assignment: turning conceptual design into physical reality. Once more, this dictated a good balance of healthy self-esteem versus courteous trust and respect in the other parties for the partnership to work. 
For instance, if a design did not work out quite well in the construction phase, who was to blame - the designer or the builder? As far as Khun Chaowalit was concerned, he would prefer that his various colleagues resorted to the blaming game as seldom as possible. Yet, with such a threesome of esteemed and proud professional groups - not a piece of cake either.

The above illustrate but a few examples of the myriad partnerships of professionals simultaneously transpiring at CDW. Moreover, these many professional partnerships often overlapped one another thereby complicating the situation even further. Given the countless professions that made up the CDW's symphony orchestra - architects, designers, draftsman, engineers, foremen, mechanics, technicians, attorneys, accountants, quality controllers, and others - Khun Chaowalit and his fellow project managers indeed needed to constantly exercise their conductor-like skill to create a harmonic project execution. Even for a maestro like Khun Chaowalit, this was still not a piece of cake, although he apparently must somehow make it his cup of tea.

\subsection{Partnership of organizations}

Finally, Khun Chaowalit stood yet at another crucial junction in CDW's operation, one between the alliance and three indispensible external parties: the clients, the contractors/sub-contractors, and the authority. With all these three external parties, he had to orchestrate still another special partnership where all factions must uphold their functions, while contending with the views of the other partner(s).

Take CDW's relationship with the clients, for example. Convincing the clients to take up the best decisions and actions possible constitutes a hallmark of excellent consultancy. Coming up with proficient advices was critical but usually straightforward, because it was after all what CDW professionals were trained and qualified to deliver. The architects, designers, engineers, mechanics, and other specialists generally had no real difficulty delivering expert advices vis-à-vis their professions. Yet, necessary as smart advices were, they in themselves were certainly not sufficient. The clients had to see and agree that these were indeed 'smart' - a matter not as straightforward. For one thing, what about the old adage that the customer is always right'? Now, that is not always the case with consultancy. In fact, 
in the consultancy business, customers cannot always be right, else why would they seek the consultants' expert advice in the first place.

Nevertheless, a client is a client is a client, and consultants must always walk the fine line between upholding their expertise without offending the clients. They must confront and challenge the clients when the clients are not quite right, eventually convincing the clients to take up their advices. The ability to handle this oxymoronic condition is the key to consultancy business. It requires a good interplay of confidence, trust, respect and assertiveness. Interestingly, Khun Karel, CDW President, observed that the Dutch appeared to be better at this little game, particularly when it concerned Dutch or Western clients who were used to separating emotion from subject matter, yet another reason for the need to have expatriate involvement. Khun Chaowalit, on the other hand, also witnessed how in some circumstances involving Thai clients, a touch of Thainess was often called for to establish good rapport. Still, for some other instances, a dose of opposite cultural tendency turned out to be more useful, such as when a stubborn Thai client would listen with less feeling of losing face to a blunt expert foreigner. Take the historic case mentioned earlier when Khun Chuchawal turned to Khun Geert to deal with a Thai client, for example. Khun Chuchawal suspected that as a Thai, the 'kraeng jai' notion could make it awkward, if not impossible, for him to confront the Thai client with a dose of strong medicine. Khun Geert, in his Dutch cloak, could deliver the difficult message more easily.

All things considered, in most cases, a combined Dutch-Thai team proved to be the most effective for CDW. Whatever the case maybe, though, partnership with the clients demanded that CDW professionals must balance well the respect for their own professions, for their clients, and for the end results. These three distinct types of respect were not automatically in harmony and the Project Manager like Khun Chaowalit stood always at the center of the balancing act.

The same applied to the partnerships with outside contractors and official authorities, two external parties CDW needed to constantly concur with who did not necessarily see eye to eye with the firm's agenda. Contractors, such as construction companies or other specialists, naturally had their own business agendas to tend too, agendas that might or might not be in line with those of CDW's. Yet CDW must work with them to ensure successful completion of projects, much in the same way as with the clients, 
only maybe in a reverse fashion. Finally, CDW must also deal with governmental agencies on a regular basis. The need to obtain a variety of permits alone meant that CDW must concur with many public offices, a transaction where local practice and international standard must form a harmonious agreement. Therefore, partnership with local authority became another balancing act of diverse organizational cultures.

Khun Chaowalit and other project managers functioned at the hub of all these partnerships: of nationals, professionals, and organizationals. Their main instrument to orchestrate these partnerships was to convince all partners that they were all in it together - for better rather than for worse, for richer rather than poorer.

Thus, life went on at CDW, in spite of and because of the frictions and puzzles created by the odd-eyed identity of this strategic alliance. It was as it was and most at CDW had learned to live with or even thrive in it. Here and there, one may hear some jarring notes or see some out-of-step moves. But, after more than three decades of successful operation, CDW was certainly not out of tune or step in any major fashion. De wereld draait door. ${ }^{7}$ And as the world turned, life went on. All things considered, it seemed to be a rather intriguing world and rewarding life at the odd-eyed CDW - the fact that the alliance now ranks among the top in their industry in both the Thai and regional markets serves as a testimonial to this assertion.

\subsection{Multi-level cultural partnership as strategic trademark of CDW}

The most striking imprint of the origin and evolution of CDW was how cultures, in various shapes and forms, and their particular mode of crossing, served as a virtual trademark of competence for CDW. As a company that operated in an industry dependent upon perception and promise of competence, CDW needed to carry a prominent mark of distinction, something that conveyed past success as well as warranted future fulfilment. Success and fulfilment were of course in the eye of the beholder and since CDW had many groups of beholders, it needed to carry a trademark of competence that has many facets to attract the various beholders.

Hence, multi-faceted national culture is the first distinctive trademark of competence for CDW. For Western or Dutch clients, Dutch ownership served as a trademark of international competence; for Thai clients, Thai 
involvement that of local fluency. For all clients, its Dutch-Thai alliance afforded a trademark of desirable combined expertise. In all these instances, a particular national culture, or a unique combination thereof, served as a trademark of an exclusive type of proficiency, the reason Khun Karel, the President, emphasized the value of a 'combined' team, which epitomized the unique trademark of the total sum of CDW's competence.

Professional culture was of course another distinct trademark of CDW's competence. Granted, most, if not all, professionals at CDW were legally certified; yet legal certificate was but one stamp of qualification. Generally, each profession has its own culture, which bonds the members of each profession to one another and guards them against those outside of their circle. The 'guarding' function of professional culture trademark had a decisive role at $\mathrm{CDW}$ because the firm operated in a consultancy business where professional advices must carry dominant weight when set against clients' stance. It was not only the material capability of the professionals, but their authoritative aura and clout that made them an equal partner, not a mere servant, to the clients. Hence, CDW had to retain its 'professional' eye colour on par with that of its client - another odd-eyed instance.

CDW also needed to blend many organizational cultures in its simultaneous dealing with clients, suppliers, contractors and governmental agencies. Each of these organizations had its organizational culture that was a particular blend of internal and sectoral cultures, at the very least. The competence of CDW as a consultancy must be constantly upheld by successful management of the partnership of its own organizational culture with those of these other establishments. As mentioned earlier, as a consultancy, CDW had to maintain its own standards without denting the prestige of these other business partners and clients - once more, an oddeyed sort of balance.

\subsubsection{The significance of context in strategic alliances}

The odd-eyed personality of CDW is thus a unique case of cultural crossing. The uniqueness of the odd-eyed characteristic is in its contending yet bonding condition. CDW needed this particular instance of cross-cultural identity. It created constant tension yet it provided the very lifeblood of the alliance's existence. Because the odd-eyed identity was the cultural trademark of competence that the joint venture needed for its chosen 
business, the alliance's context in effect defined its operative identity and qualified its eventual livelihood.

Consequently, the story of CDW illustrates vividly how significant context is in any cross-cultural encounter. In the final analysis, what matters is the total sum of a particular context. To wit, there are no two CDWs, so to speak, and if we want to understand what is going on at a particular strategic alliance, we need to take its general and specific context into account, simultaneously. Although all cases of a cross-cultural platform share the same general properties, the eventual identity of each setting is unique unto itself. This makes an analysis of context indispensible if we were to truly understand a particular case of strategic alliance.

For example, in the case of CDW, the context defined the definite type of partnership and the exact mode and nature of cross-cultural condition for the alliance. First and foremost, the combined context of its industry and its niche business made the cultural odd-eyed quality a necessary trademark of its competence. Additionally, other conditions and entities that made up the alliance all contributed to how CDW was what it was. Finally and just as importantly, the context also defined the eventual effectiveness of the crosscultural condition itself. In brief, if a cross-cultural condition contributes to the prime objective of an alliance, then it is effective, despite and because of all the oddities and difficulties it creates.

\subsubsection{The significance of cross-cultural instrument in strategic alliances}

The case of CDW also illuminates the significance of having the right instrument to foster the desired (and perhaps desirable) cross-cultural mode. Because the reciprocal mode characterized CDW's prevalent cross-cultural condition, at the time of this narration, the importance of mediator as the key instrument became evident.

A mediator refers to any instrument that acts as a 'go between' for difference parties in order to render a mediate effect (Ulijn and St Amant 2000). The need for a 'go between' arises from some fundamental differences that call for a certain level of synchronization before the parties can interact with a tolerable level of friction, incompatibility or detrimental side effect. A mediator comes in a variety of shapes and forms, each performing synchronization in different manners. From our study, we theorize three primary functions that a mediator can perform - as a bumper, a connector, 
and a translator. Acting as a bumper is the crudest and most basic function of a mediator and serves a simple purpose of collision control through sheer diversion or absorption. A mediator, when acting as a bumper, simply absorbs or diverts potential frictions that result from differences. Connecting is the second function a mediator can perform. As a connector, a mediator provides a channel for exchange and reconciliation. The need for a connector arises from any sort of distances or incompatibilities - conceptual or physical - that exist among different parties. The final primary function of a mediator is as a interpreter. As the name implies, this mediating function serves to translate or, better yet, interpret meanings in one culture into their equivalent in another culture. The simplest example of a translator is of course a dictionary and the most sophisticate example of a cultural interpreter is arguably a cultural theorist and his or her messages.

Various mediators were active at CDW. As we see, although the tension was certainly there, a mechanism must have been in place that prevented it from degenerating into total negativity: the mechanism came in the form of numerous mediators. First were the human mediators in the figures such as Khun Busara and Khun Chaowalit. Both actors operated at the center of critical activities in CDW and both acted as mediators for the many forms of partnerships at CDW as illustrated in the case. In the case of the cofounders - Khun Geert and Khun Chuchawal - however, the mediator took the form a 'common denominator' that was the mutual need and appreciation in each other's contributions to the partnership.

The importance of mediator exemplified in the story of CDW provides a strong hint at the significance of a key instrument in cross-cultural interchanges. Two other types of cross-cultural instruments are indicated in Table 1, making up the three types of key instrument - controller, mediator, and hydridizer, each serving different purposes and suitable for different situations. The case of CDW illustrates the critical role that the right instrument can play in the success of a strategic alliance. Although Table 1 locates each key instrument to a particular mode of cross-cultural condition, it should be noted that, as in most issues pertaining to cultural analysis, real world settings are never as clear-cut as a theorized taxonomy. In many, if not all, cross-cultural conditions, any of the key instruments may be in force, and even more than one instrument may be employed simultaneiously. Once again, the significance of context comes into play regarding this issue. 
Such is our interpretation of CDW as an odd-eyed strategic alliance. Although we do not claim to achieve an exhaustive analysis of the case and our proposed theory, we believe we offer illuminating interpretations of both.

\section{Conclusion}

We attempt to illustrate how an interpretation of a real world case of a single strategic alliance could elucidate the inherent complex cross-cultural condition underlying strategic alliances. Our analysis is but one interpretation of only one particular case. Yet in the tradition of Clifford Geertz (1993), we believe, as Simons (1996, p. 227) espoused, that the value of a case study lies not in a statistical 'sample of one' fashion, but rather in its interpretive paradox, that is '[b]y studying the uniqueness of the particular, we come to understand the universal'. In the same vein, we believe that the particular strategic alliance that was CDW could help us understand more the universal of strategic alliances.

Among the 'universal' that the case of CDW as an odd-eyed cat has illustrated are the followings. First, as stated at the very beginning, strategic alliances inherently dictate cultural crossing, at many levels. It follows that better understanding of the role culture plays and the complexity this role can take will enrich our collective effort in the inquiry into strategic alliances - their origin, development and outcome. Second, the many shapes and forms of cultural crossing, as proposed in our theorization, suggest that the range of how cultural forces can influence, or even define, the nature and performance of strategic alliances is not a simple cut-and-dried matter. The insights we gain from our study indicate that further probe into the role of culture could shed more lights into the effort to understand the success and failure of strategic alliances, when viewed from a cultural perspective. Last, our presentation of the odd-eyed CDW may help convince scholars in strategic alliances of the value that a qualitative, interpretative view of the issue could deepen our reading of real world phenomena and provide complementary insights to those that already gained by the sister quantitative approach. As the thick-descriptive style of the case reveals, in every story of a strategic alliance, multiple living actors breathe and live through its success or failure. In the final analysis, these actors are what 
make or break the alliances and it seems prudent to listen carefully to the stories they have to tell.

\section{Endnotes}

1 To preserve informants' privacy and anonymity, all characters names are fictitious, and, to give local flavour to the narration, they are addressed in Thai's convention with the Thai 'Khun', which is equivalent to Mr. or Mrs. in English, followed by the first name, except when first introduced. Character job titles follow what they were in real life.

2 In Dutch, two forms of second person pronoun exist: the formal ' $u$ ' and the intimate 'je.' Interestingly, the Thai language has a similar, although much more elaborated, system of distinction in the proper use of all pronouns (a subject that deserves an entire chapter in itself).

3 'Kraeng jai' is one of those Thai terms and traits that are hard to translate, let alone explicate. Briefly, it refers to the tendency to avoid any act or word that could harm someone's feeling, put him or her in an awkward position, cause him or her to loose face, or create inconvenience to any party involved. This usually results in an avoidance of direct confrontation altogether. See Komin (1991) for further details.

4 'Farang' is a Thai word for Westerner, most likely originating from the English word 'foreigner' or 'foreign'.

5 The terminology 'steady state' follows its use in the discipline of computer simulation in general and discrete event simulation in particular. Because of its relative neutrality, we prefer this term to its alternative in economics - 'equilibrium'. However, we use the term here in a very broad sense and do not embrace all the fine properties and implications of the terminology as used in the above two disciplines.

6 Feng shui is '(in Chinese thought), a system of laws considered to govern spatial arrangement and orientation in relation to the flow of energy ... and whose favourable or unfavourable effects are taken into account when sitting and designing buildings' (Oxford University Press 1989: 674)

7 Literally, this translates into 'The world continues to turn'. Figuratively, it has the same connotation as the English expression 'Life goes on'. The daily Dutch television talk/variety show De Wereld Draait Door, which was running successfully at the time of this writing, inspired our use of it here. 


\section{References}

Adler, Nancy J (2002), International Dimensions of Organizational Behavior (4th ed.), Cincinnati, Ohio: South-Western.

Adler, Nancy J (1983), 'A Typology of Management Studies Involving Culture', Journal of International Business Studies, 14 (2), 29-47.

Boyacigiller, Nakiye Avdan, M Jill Kleinberg, Magaret E Phillips and Sonja A Sackmann (2004), 'Conceptualizing Culture: Elucidating the Streams of Research in International Cross-Cultural Management', in Punnett, Betty Jane and Oded Shenkar, (eds), Handbook for International Management Research, 2nd ed., Ann Arbor: The University of Michigan Press.

Chase, Susan E. (2005), 'Narrative Inquiry: Multiple Lenses, Approaches, Voices', in Denzin, N. K. and Y. S. Lincoln, (eds), The Sage Handbook of Qualitative Research, 3rd ed., Thousand Oaks, CA: Sage Publications.

Dyer, W. Gibb, Jr. and Alan L. Wilkins (1991), 'Better Stories, Not Better Constructs, to Generate Better Theory: A Rejoinder to Eisenhardt', The Academy of Management Review, 16 (3), 613-19.

Eisenhardt, Kathleen M. (1991), 'Better Stories and Better Constructs: The Case for Rigor and Comparative Logic', The Academy of Management Review, 16 (3), 620-27.

Geertz, Clifford (1993), The Interpretation of Cultures: Selected Essays, London: Fontana Press.

Hofstede, Geert (2001), Culture's Consequences: Comparing Values, Behaviors, Institutions, and Organizations across Nations (2nd ed.), London: Sage Publications.

Hofstede, Geert (1980), Culture's Consequences: International Differences in Work-Related Values. (1st ed.), Beverly Hills, CA: Sage Publications.

Hofstede, Geert and Geert Jan Hofstede (2005), Cultures and Organizations: Software of the Mind (2nd ed.), New York: McGraw-Hill.

Huntington, Samuel P. (1996a), The Clash of Civilizations and the Remaking of World Order, New York: Simon \& Schuster.

Huntington, Samuel P. (1993), 'The Clash of Civilizations?' Foreign Affairs, 72 (3), 22-49.

Huntington, Samuel P. (ed (1996b), The Clash of Civilizations? The Debate, New York: Foreign Affairs.

Jackson, Terence and Zeynep Aycan (2006), 'From Cultural Values to Cross Cultural Interfaces', International Journal of Cross Cultural Management, 6 (1), 5-13.

Jackson, Terence and Zeynep Aycan (2001), 'International Journal of Cross Cultural Management-Towards the Future', International Journal of Cross Cultural Management, 1 (5-9). 
Kogut, Bruce (1988), 'Joint Ventures: Theoretical and Empirical Perspectives', Strategic Management Journal, 9 (4), 319-32.

Komin, Suntaree (1991), Psychology of the Thai People: Values and Behavioral Patterns, Bangkok: National Institute of Development Administration (NIDA).

Kroeber, Alfred L. and Clyde Kluckhohn (1963), Culture: A Critical Review of Concepts and Definitions (New ed.), New York: Random House.

Kwanjai, Nantawan Noi (forthcoming), 'Cross-Cultural Intelligence Amidst Intricate Cultural Webs: A Tale of the UnDutchables in the Land of 1001 Smiles', Maastricht University.

Kwanjai, Nantawan Noi and J Friso den Hertog (2008), 'Cultural Intelligence: A Qualitative Angle', paper presented at the 24th European Group for Organizational Studies (EGOS) Colloquium, 10-12 July 2008, Amsterdam: Vrij University Amsterdam.

Mohr, Jakki and Robert Spekman (1994), 'Characteristics of Partnership Success: Partnership Attributes, Communication Behavior, and Conflict Resolution Techniques', Strategic Management Journal, 15 (2), 135-52.

Oxford University Press (ed (1989), Oxford English Dictionary (2nd ed.), Oxford: Oxford University Press.

Park, Seung Ho and Gerardo R. Ungson (1997), The Effect of National Culture, Organizational Complementarity, and Economic Motivation on Joint Venture Dissolution', The Academy of Management Journal, 40 (2), 279-307.

Roberts, Karlene H (1970), 'On Looking at an Elephant: An Evaluation of Cross-Cultural Research Related to Organizations', Psychological Bulletin (74), 327-50.

Schneider, Susan C. and Jean-Louis Barsoux (2003), Managing across Cultures (2nd ed.), New York: Prentice Hall.

Simons, Helen (1996), 'The Paradox of Case Study', Journal of Education, 26 (2), 225-40.

Spekman, Robert E., Theodore M. Forbes Iii, Lynn A. Isabella and Thomas C. MacAvoy (1998), 'Alliance Management: A View from the Past and a Look to the Future', Journal of Management Studies, 35 (6), 747.

Stake, Robert E. (1995), The Art of Case Study Research, Thousand Oaks, CA: Sage Publications.

Stake, Robert E. (2000), 'Case Studies', in Denzin, N. K.,Y. S. Lincoln and E. G. Guba, (eds), Handbook of Qualitative Research, 2nd ed., Thousand Oaks, CA: Sage Publications.

Stake, Robert E. (1978), 'The Case Study Method in Social Inquiry', Educational Researcher, 7 (2), 5-9.

Stake, Robert E. (2005), 'Qualitative Case Studies', in Denzin, N. K. and Y. S. Lincoln, (eds), The Sage Handbook of Qualitative Research, 3rd ed., Thousand Oaks, CA: Sage Publications. 
Stake, Robert E. and Deborah J. Trumbull (1982), 'Naturalistic Generalizations', Review Journal of Philosophy \& Social Science, 7 (1), 1-12.

Ulijn, Jan (2000), 'Innovation and International Business Communication: Can European Research Help to Increase the Validity and Reliability for Our Business and Teaching Practice?' Journal of Business Communication, 37 (2), 173-87.

Ulijn, Jan and K. St Amant (2000), 'Mutual Intercultural Perception: How Does It Affect Technical Communication, Some Data from China, the Netherlands, Germany, France and Italy', Technical Communication, 47 (2), 220-37.

van der Blonk, Heico (2003), 'Writing Case Studies in Information Systems Research', Journal of Information Technology, 18, 45-52. 


\section{The UNU-MERIT WORKING Paper Series}

2008-01 Science, Technology and Development: Emerging concepts and visions by Luc Soete

2008-02 Reframing technical change: Livestock Fodder Scarcity Revisited as Innovation Capacity Scarcity. Part 1. A Review of Historical and Recent Experiences by Andy Hall, Rasheed Sulaiman V., Mona Dhamankar, Peter Bezkorowajnyj \& Leela Prasad

2008-03 Reframing technical change: Livestock Fodder Scarcity Revisited as Innovation Capacity Scarcity. Part 2. A Framework for Analysis by Andy Hall, Rasheed Sulaiman, V. and Peter Bezkorowajnyj

2008-04 Reframing technical change: Livestock Fodder Scarcity Revisited as Innovation Capacity Scarcity.Part 3. Tools for Diagnosis and Institutional Change in Innovation Systems by Andy Hall, Rasheed Sulaiman and Peter Bezkorowajnyj

2008-05 Is Inter-Firm Labor Mobility a Channel of Knowledge Spillovers? Evidence from a Linked Employer-Employee Panel by Mika Maliranta, Pierre Mohnen \& Petri Rouvinen

2008-06 Financial Constraints and Other Obstacles:Are they a Threat to Innovation Activity? By P. Mohnen, F.C. Palm, S. Schim van der Loeff and A. Tiwari

2008-07 Knowledge-based productivity in 'low-tech' industries: evidence from firms in developing countries by Micheline Goedhuys, Norbert Janz and Pierre Mohnen

2008-08 The Voyage of the Beagle in Innovation Systems Land.Explorations on Sectors, Innovation, Heterogeneity and Selection by Martin Srholec \& Bart Verspagen

2008-09 Crafting Firm Competencies to Improve Innovative Performance by Boris Lokshin, Anita van Gils \& Eva Bauer

2008-10 The Economics and Psychology of Personality Traits by Lex Borghans, Angela Lee Duckworth, James J. Heckman \& Bas ter Weel

2008-11 Embedding Research in Society: Development Assistance Options for Supporting Agricultural Innovation in a Global Knowledge Economy by Andy Hall

2008-12 Playing in Invisible Markets: Innovations in the Market for Toilets to Harness the Economic Power of the Poor by Shyama V. Ramani

2008-13 Explaining Success and Failure in Development by Adam Szirmai

2008-14 Running The Marathon by William Cowan, Robin Cowan and Patrick Llerena

2008-15 Productivity effects of innovation, stress and social relations by Rifka Weehuizen, Bulat Sanditov and Robin Cowan

2008-16 Entrepreneurship and Innovation Strategies in ICT SMEs in Enlarged Europe (EU25) by Kaushalesh Lal and Theo Dunnewijk

2008-17 Knowledge Transfers between Canadian Business Enterprises and Universities: Does Distance Matter? By Julio M. Rosa \& Pierre Mohnen

2008-18 Multinationals are Multicultural Units: Some Indications from a Cross-Cultural Study by Nantawan Noi Kwanjai \& J. Friso den Hertog 
2008-19 The Innovativeness of Foreign Firms in China by Branka Urem, Ludovico Alcorta and Tongliang An

2008-20 Beyond the emission market: Kyoto and the international expansion of waste management firms by Ionara Costa, Asel Doranova and Geert-Jan Eenhoorn

2008-21 The 'making of' national giants: technology and governments shaping the international expansion of oil companies from Brazil and China by Flavia Carvalho and Andrea Goldstein

2008-22 If the Alliance Fits . . . : Innovation and Network Dynamics by Robin Cowan \& Nicolas Jonard

2008-23 Facing the Trial of Internationalizing Clinical Trials to Developing Countries: With Some Evidence from Mexico by Fernando Santiago-Rodriguez

2008-24 Serving low-income markets: Rethinking Multinational Corporations' Strategies by Shuan SadreGhazi and Geert Duysters

2008-25 A percolation model of eco-innovation diffusion: the relationship between diffusion, learning economies and subsidies by Simona Cantono and Gerald Silverberg

2008-26 New Europe’s Promise for Life Sciences by Sergey Filippov and Kálmán Kalotay

2008-27 A closer look at the relationship between life expectancy and economic growth by Theophile T. Azomahou, Raouf Boucekkine, Bity Diene

2008-28 Regional Capital Inputs in Chinese Industry and Manufacturing, 1978-2003 by Lili Wang \& Adam Szirmai

2008-29 Worker remittances and government behaviour in the receiving countries by Thomas Ziesemer

2008-30 Strategic motivations for Sino-Western alliances: a comparative analysis of Chinese and Western alliance formation drivers by Tina Saebi \& Qinqin Dong

2008-31 Changing Configuration of Alternative Energy Systems by Radhika Bhuyan and Lynn Mytelka

2008-32 Promoting clean technologies: The energy market structure crucially matters by Théophile T. Azomahou, Raouf Boucekkine, Phu Nguyen-Van

2008-33 Local Knowledge Spillovers, Innovation and Economic Performance in Developing Countries: A discussion of alternative specifications by Effie Kesidou and Adam Szirmai

2008-34 Wage effects of R\&D tax incentives: Evidence from the Netherlands by Boris Lokshin and Pierre Mohnen

2008-35 Cross-border Investment and Economic Integration: The Case of Guangdong Province and Hong Kong SAR by Naubahar Shari and Can Huang

2008-36 Radical versus non-radical inventions by Wilfred Schoenmakers, Geert Duysters \& Wim Vanhaverbeke 
2008-37 Localized Innovation, Localized Diffusion and the Environment: An Analysis of $\mathrm{CO}_{2}$ Emission Reductions by Passenger Cars, 2000-2007 by Bart Los and Bart Verspagen

2008-38 The economic impact of AIDS in sub-Saharan Africa by Théophile T. Azomahou, Raouf Boucekkine, Bity Diene

2008-39 Further results on bias in dynamic unbalanced panel data models with an application to firm $R \& D$ investment by Boris Lokshin

2008-40 A multilevel analysis of innovation in developing countries by Martin Srholec

2008-41 Experimentation with strategy and the evolution of dynamic capability in the Indian Pharmaceutical Sector by Suma Athreye, Dinar Kale \& Shyama V. Ramani

2008-42 The Impact of Social Capital on Crime: Evidence from the Netherlands by I.Semih Akcomak and Bas ter Weel

2008-43 Portrait of an Odd-Eyed Cat: Cultural Crossing as a Trademark for a Dutch-Thai Strategic Alliance by Nantawan Noi Kwanjai \& J Friso den Hertog 